\title{
POPULATION STRUCTURE OF A DOMINANT HALOXYLON SPECIES, ACROSS A HABITAT GRADIENT IN THE SOUTHERN GURBANTUNGGUT DESERT, CENTRAL ASIA
}

\author{
YANG, R. H. ${ }^{1,2,3}-$ ZHAO, C. Y. ${ }^{2 *}-$ WANG, X. J., ${ }^{2,3}-$ YANG, Y. G. $^{2}-$ LI, Y. K. ${ }^{2}$ \\ ${ }^{I}$ XinJiang Education Institute, Urumqi 840043, China \\ ${ }^{2}$ Xinjiang Institute of Ecology and Geography, Chinese Academy of Sciences \\ Urumqi 830011, China \\ ${ }^{3}$ Xinjiang Agriculture University, Urumqi 830052, China \\ (phone: +86-991-876-3007; fax: +86-991-876-3007) \\ *Corresponding author \\ e-mail: zcy@ms.xjb.ac.cn \\ (phone: +86-991-788-5307; fax: +86-991-788-5307) \\ (Received $8^{\text {th }}$ Mar 2017; accepted $7^{\text {th }}$ Jun 2017)
}

\begin{abstract}
In the context of habitat change, widely distributed vegetation can serve as relevant barometers of ecosystems' sensitivity or resilience to disturbances. This study analyzed morphological variations in trees and recruits density, individual size and their spatial structure through Haloxylon population's field experiment in each sampling location. Our results showed a significant decrease in tree density from the south (4445 trees/ ha) to the central desert (481 trees/ ha), whereas basal diameter, crown radius and height showed different tendency. Tree basal diameter and height structure of populations had positively skewed asymmetric distributions with "reverse J" shape. Tree density in the valleys between dunes (6133 trees/ha) was greatest. Few recruits were found in the central desert, but their density increased from central to south of the Gurbantunggut desert ,perhaps owing to seed rain patterns and availability of soil moisture and nutrients. Trees had a spatially clustered distribution in all study plots. Haloxylon spp. can tolerate wide climatic and habitat fluctuations, however recruitment can be unpredictable in harsh desert conditions. Soil physicochemical properties were the main ecological factor influencing spatial patterns. With increasing altitude, soil moisture and nutrient contents decreased significantly. In different dune habitats, Haloxylon population had different characteristics.
\end{abstract}

Keywords: latitudinal variation; cluster; recruitment; morphological traits; spatial structure

\section{Introduction}

Plant species with wide distribution ranges are exposed to a great variety of climatic and habitat conditions. Individuals and populations react to wide amplitudes of environmental factors through varying responses (Swenson and Enquist, 2007; Aitken et al., 2008; Wu et al., 2013). Developing broad adaptation strategies is particularly a requirement for species that are distributed along a large latitudinal gradient including both dry and humid areas (Aitken, 2008; Bognounou et al., 2009). Severe environmental degradation (e.g., decreases in river flows, a drop in underground water levels, overdevelopment in agriculture, overgrazing of animals, and mean temperature increases) has often led to an expansion of the desert area in the Gurbantunggut, causing high mortality in some woody desert species and radically changing their population structures (Huang et al., 2009; Allan et al., 2012; Si, 2010). The observed dwindling of natural Haloxylon forested areas has raised serious concerns for managers, scholars and scientists. One documented long-term consequence of anthropic disturbances is a shift 
in affected species' ranges (Lykke et al., 1999). However, although drought frequency and severity are predicted to increase across continental interiors, the consequences of these changes for dominant plant species are largely unknown (Mueller et al., 2005).

In the Gurbantunggut desert, there is little documentation of the distributions of plant species, and how these ranges are shaped by environmental factors is poorly understood (Qian et al., 2007). Several ecological investigations have examined the population structures and dynamics of some useful tree species in many parts of Asia and Africa, at both local (Nacoulma et al., 2011; Ivanov et al., 2008; Wu et al., 2013) and national scales(Sambare et al., 2011; Fandohan et al., 2011). However, few of these have specifically addressed widely distributed species in any great detail. This is the case for Haloxylon, that has an exceptional ecological amplitude, and includes the main woody species in central Asian desert ecosystems and artificial afforestation systems (Huang et al., 2009). It is also designated the king of psammophytic plants, owing to its important role in sand fixation, wind control and water conservation in the desert (Zhu et al., 2004). However, recent anthropogenic pressures, such as the expansion of agriculture, threaten both planted, artificial forests and natural populations of Haloxylon in China. Previous studies have suggested that Haloxylon needs effective conservation attention in natural stands in order to guarantee its persistence and to avoid a shortage of its products (Liang and Zhao, 1982). One of the main reasons for poor regeneration in Haloxylon is the high mortality of recruits $(\mathrm{Si}, 2010)$, likely because of very low water availability in soils. Understanding population patterns and underlying intrinsic characteristics is necessary for the conservation and sustainable management of widespread species distributed across biomes. Further more, the study of plant population characteristics is helpful for theoretical understanding of species coexistence and population structures, both of which are largely dependent on spatial patterns (Kikkawa and Anderson, 1984; Dale, 1999). Such quantitative and spatial patterns may be derived from processes and forces operating on different scales, such as heterogeneity in soil conditions, intra- and inter-specific competition, seed dispersal and other environmental factors (Jeltsch et al., 1999; Saei et al., 2014). For efficient conservation management of Haloxylon, detailed, large-scale analyses of its population ecology are necessary. The aim of this study was to document Haloxylon populations spanning a latitudinal gradient, from the extreme south of Gurbantunggut desert to the central desert. Specifically, we aimed to assess the structural patterns of populations spanning the latitudinal gradient; examine tree morphological traits (height, diameter, number of stems) across phytogeographical zones and analyze the spatial distribution patterns of Haloxylon individuals in natural stands.

\section{Materials and methods}

\section{Study area}

The study was conducted over the 2013 growing season, with three sampling transects situated in the Gurbantunggut desert $\left(44^{\circ} 11^{\prime}-46^{\circ} 20^{\prime} \mathrm{N}, 8431^{\prime}-9000^{\prime} \mathrm{E}\right)$, which is a part of Junggar Basin (Fig. 2) and has an area of $48000 \mathrm{~km}^{2}$. This desert is located in the hinterland of the Eurasian continent, within the Xinjiang region in northwest China. Haloxylon species are dominant components of the vegetation in the Gurbantunggut, as in all sandy and clay deserts across Central Asia. The desert is composed mainly of longitudinal dunes, although checkerboard- and honeycombshaped dunes are also present (Wang, 2003); he dunes vary in mobility from completely 
movable dunes, to semi-stable and stable dunes. The longitudinal dunes range in length from several hundred meters to tens of kilometers, have a height of $10-50 \mathrm{~m}$, and generally run in a north to south direction (with the western slope very long and shallow, and the eastern slope short and steep) (Wang, 2002). Gurbantunggut desert has sandy soil and a continental, arid temperate climate, which is characterized by two contrasting seasons (cold winters and hot dry summers), owing to its great distance from the ocean. Seasons vary dramatically, with winter (December-February), spring (March-May), summer (June-August) and autumn (September-November) climatic conditions affecting plant growth cycles differently (Nyongesah and Wang, 2013). From 2003 to 2013 , the coldest month is January $\left(-19.50 \sim-22.11^{\circ} \mathrm{C}\right)$ and the hottest month is July $\left(23.13 \sim 27.69^{\circ} \mathrm{C}\right)$. The average annual temperature is $6.86 \sim 7.73^{\circ} \mathrm{C}$. Precipitation ranges from 97.2 to $180 \mathrm{~mm}$, with winter and spring precipitation accounting for about two-thirds of the annual total (Qian et al., 2011). Moreover, precipitation varies spatially across the Gurbantunggut desert hinterland and surrounding areas (Fig. 1). The annual potential evaporation is $2000-2800 \mathrm{~mm}$ (Song et al., 2011). Wind speeds are greatest during late spring each year, with an average velocity of $11.17 \mathrm{~m} / \mathrm{s}$, and winds come predominantly from the west-northwest, northwest and north. Natural vegetation is sparse and the water table can be extremely deep $(8-300 \mathrm{~m})$, although this is variable. In the study area, the vegetation is dominated by desert species, particularly Chenopodiaceae species, and species richness is relatively high. Common dwarf shrub and pygmy tree species include Aristida pennata, Ceratocarpus arenarius, Ceratoides ewersmanniana, Ephedra distachya, Haloxylon ammodendron, Haloxylon persicum and so on (Qian et al., 2003).

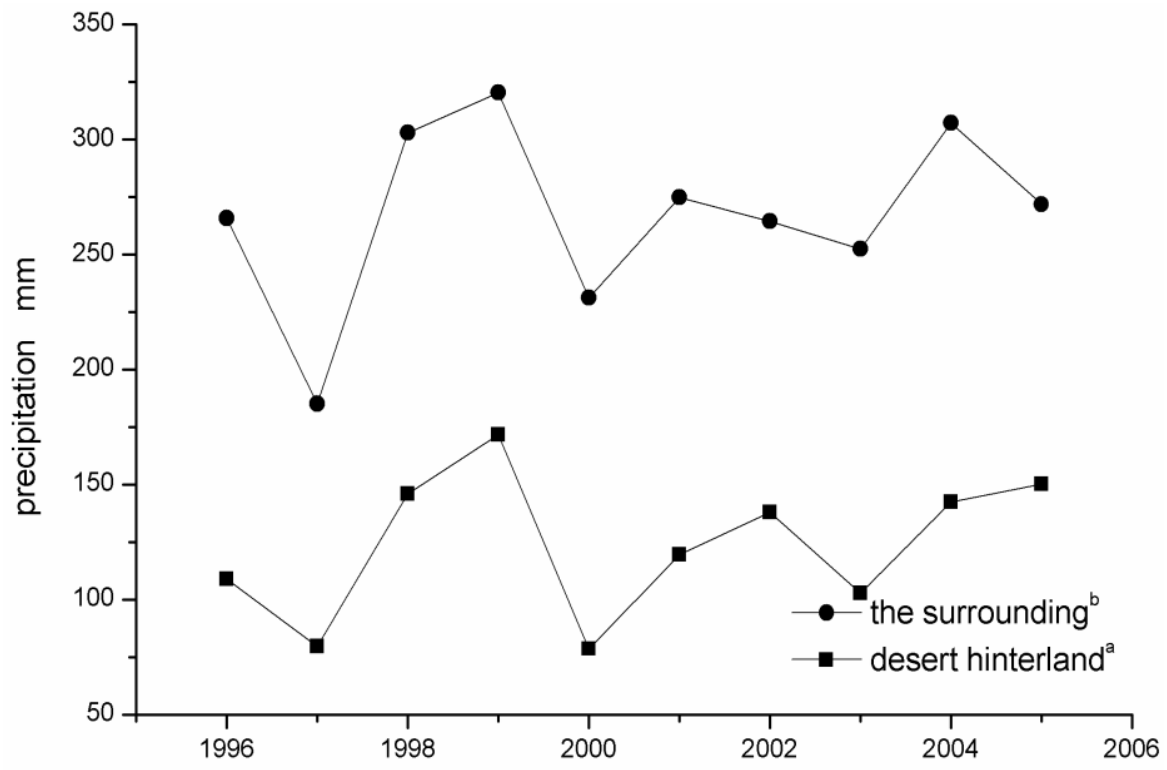

Figure 1. Comparison of precipitation in the desert hinterland and surrounding lands ${ }^{a}$ Mean yearly precipitation was derived from the meteorological stations in the desert hinterland of shixi oil field ( Liu et al., 2012).

${ }^{b}$ Mean yearly precipitation was derived from the meteorological stations of five surrounding cities (Karamay51243, Paotai51352, MoSuowan51353, Hutubi 51367, Fukang51377). 


\section{Sampling design}

Combining recent field survey data with information on the distribution of dune types from previous reports (Liu and Zao, 2009), Google Earth was used to select three sampling transects among the longitudinal ridges from south to central Gurbantunggut Desert. The first transect was in a fixed dune-dominated area (F), the second a semifixed dune-dominated area $(\mathrm{S})$ and the last a movable dune-dominated area $(\mathrm{M})$; transects were $40 \mathrm{~km}$ apart (Fig. 2). In each transect $\left(1^{\text {st }}\right.$ transect: $44^{\circ} 22^{\prime} 20.01 \mathrm{~N}$, $87^{\circ} 55^{\prime} 06.11 \mathrm{E} ; 2^{\text {nd }}$ transect: $44^{\circ} 36^{\prime} 09.40 \mathrm{~N}, 88^{\circ} 14^{\prime} 17.83 \mathrm{E} ; 3^{\text {rd }}$ transect: $44^{\circ} 56^{\prime} 52.01 \mathrm{~N}$,

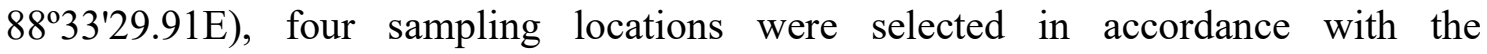
topographical characteristics of the dune: the valley between the dunes (valley), the east slope of the dune (leeward slope), the top (top) and the west slope (windward slope). Considering the dimensions of the sand dunes across transects, Haloxylon populations were surveyed in $10 \mathrm{~m} \times 10 \mathrm{~m}$ and $20 \mathrm{~m} \times 20 \mathrm{~m}$ main plots in each sampling location, with each main plot being associated with two sub-plots of $2 \mathrm{~m} \times 2 \mathrm{~m}$ to examine Haloxylon species regeneration patterns (individuals with $\mathrm{dbh} \leq 0.3 \mathrm{~cm}$ ) and survey grass species. There were 20 main plots per transect which considered sufficient for reliable assessment of Haloxylon populations, according to previous prospecting of natural stands in the study area.

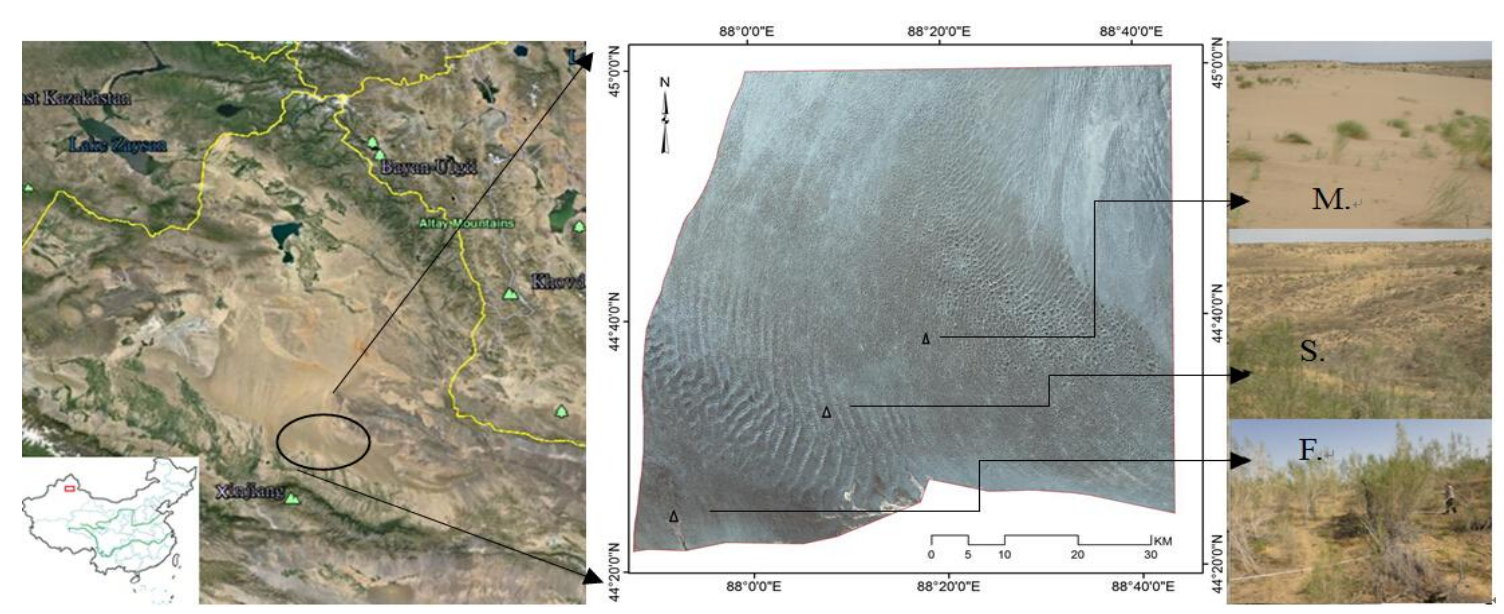

Figure 2. Position in the study area and sample design

\section{Habitat characteristics}

The study area encompassed three different ecological (phytogeographical) zones ( $\mathrm{F}$, S, and M), covering different dune types (Liu and Zao, 2009), and an altitudinal gradient from north to central Gurbantunggut. The three different zones were comprised of different sizes of sand dunes with distinct vegetation coverage and sands of different particle sizes. Environmental data for each transect, including both climate and soil traits obtained from the nearest climate stations, are provided in Table 1. The extent of the snowy and rainy period varied slightly from north to central Gurbantunggut. As shown in Table 1, mean annual precipitation (data from 2000-2010) ranged from 110.4$128.6(\mathrm{~F})$ to $86-110 \mathrm{~mm}(\mathrm{M})$, and temperatures varied about $1-4^{\circ} \mathrm{C}$ (Table 1 ). The southern most edge of the fixed dune-dominated area $(\mathrm{F})$ increased progressively in height towards the central desert, and hence soil available $\mathrm{N}$, biomass, and organic carbon content, as well as conductivity, moisture and $\mathrm{pH}$ at $0-30 \mathrm{~cm}$ soil depths 
decreased on average from the south (F) to the central (M) desert (Fig. 3). With the exception of electrical conductivity and effective $\mathrm{N}$, soil parameters differed significantly among zones. According to survey data, there were more physical and biological crusts in the S versus F and $\mathrm{M}$ transect zones. Soil nutrient availability at the top of the dunes was significantly lower than in the other plot locations, whereas bottom plots (between the dunes) had slightly higher availabilities (Fig. 3). Soil moisture in bottom plots was significantly higher than in the other plot types (Fig. 4), and decreased from valley > east side> west side > top, which is consistent with previous reports $(\mathrm{Li}$, 2013a). In the three transects, principal vegetation types included drought-tolerant plant species. The main human activities related to natural resource exploitation in the desert are agriculture and livestock farming.

Table 1. Environmental factors describing the three different ecological/elevational study zones (fixed dune dominated desert area, F.; semi-fixed dune dominated desert area, S.; movable dune dominated desert area, $M$.)

\begin{tabular}{|c|c|c|c|}
\hline Parameter & F. & S. & M. \\
\hline Mean precipitation & $110-128.6^{\mathrm{b}}$ & $100-123^{\mathrm{c}}$ & $86-110^{\mathrm{a}}$ \\
Temperature $\left({ }^{\circ} \mathrm{C}\right)$ : min-max & $-37-41.5$ & $-35-39.7$ & $-38.2-44.0$ \\
The average particle size of sand (Mz) & 0.24 & 0.42 & 0.79 \\
Elevation m & 445.6 & 574.3 & 663.3 \\
water content \% & 3.12 & 1.34 & 1.18 \\
Water table (m) & $8-12$ & $30-50$ & $>150$ \\
organic carbon g/kg & 1.04 & 0.795 & 0.365 \\
organic matter g/kg & 1.79 & 1.37 & 0.63 \\
Effective N g/kg & 0.142 & 0.110 & 0.104 \\
pH & 8.00 & 7.83 & 7.69 \\
Electrical conductivity ms/cm & 0.114 & 0.089 & 0.064 \\
physical and biological crusts & $10-20 \%$ & $30-60 \%$ & $\leq 10 \%$ \\
\hline
\end{tabular}

${ }^{\mathrm{a}, \mathrm{b}}$ same as Fig. 1 .

${ }^{c}$ Means yearly precipitation was derived from automatic monitoring performed in the desert management office.

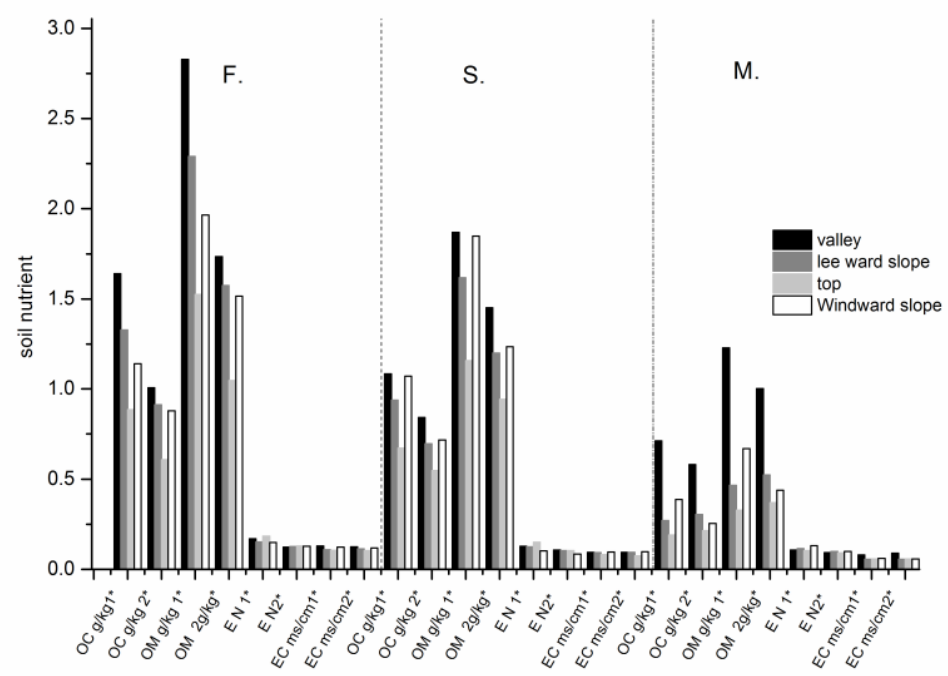

Figure 3. Soil physicochemical properties of sampling locations within study transects $(1 *, 0$ $15 \mathrm{~cm} ; 2 *, 15-30 \mathrm{~cm} ;$ OC, organic carbon; OM, organic matter; EN, Effective nitrogen; EC, Electrical conductivity) 


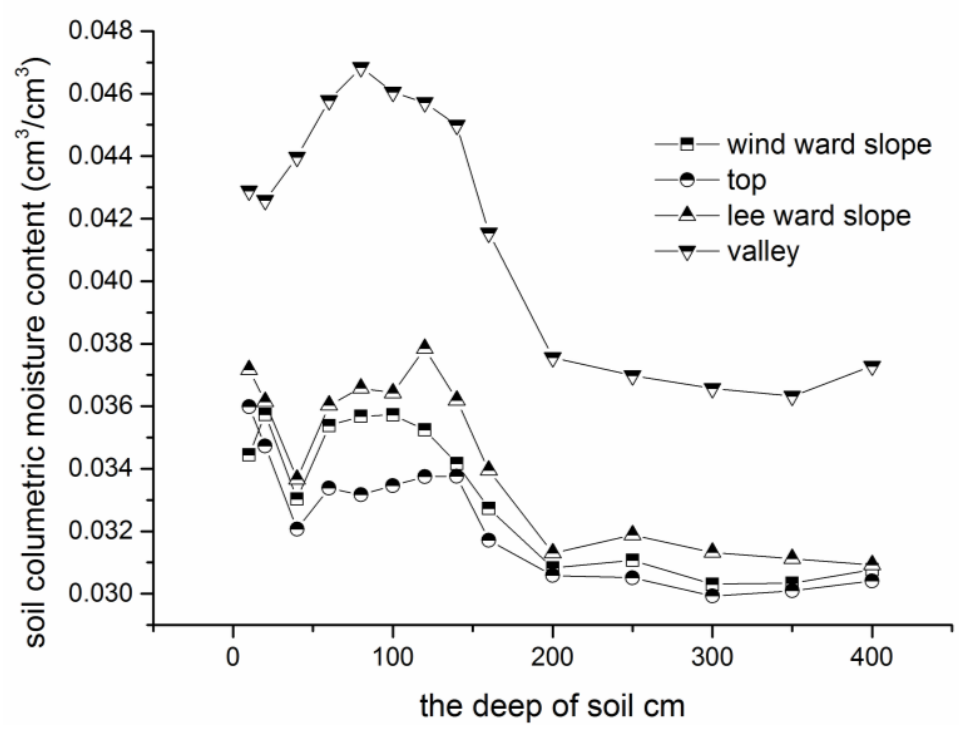

Figure 4. Comparison of soil moisture at different sample locations in F

\section{Plant surveys and statistical analysis}

In the study area, Haloxylon ammodendron and Haloxylon persicum are two dominant and keystone species. We pooled data for these two species as Haloxylon persicum occurred rarely and mainly on dune tops, and the two congeners are ecologically similar. Observations and measurements reported in this paper were made from May -July 2013. These dates roughly coincide with peak Haloxylon biomass at these localities (Hu, 1985). Haloxylon individuals were identified and measured in all plots for each transect; note that plots were arranged along an east to west sampling line. In each of the main plots, the following tree morphological parameters were measured: basal diameter, crown diameter, height and the number of stems (the number of branches off a main stem occurring below $0.5 \mathrm{~m}$ ). The Cartesian coordinates (X-Y) of each tree were also recorded in the main plots. In the sub-plots, the height as well as the number of regenerating stems was determined for each individual. Habitat factors such as direction aspect, elevation, the geographical coordinates, slope and so on were also recorded. Soil samples were collected from random locations in the four corners and the middle of each plot at depths of $0-15 \mathrm{~cm}$ and $15-30 \mathrm{~cm}$. These were sealed in airtight containers plastic bags and taken for analysis in the lab. Soil moisture was measured using the neutron probe method and by oven-drying. After passing soil through a $0.25 \mathrm{~mm}$ sieve, soil carbon and nitrogen contents were determined using the potassium chromate oxidation heating method-external heating method and the Kjeldahl method, respectively. The soil was washed with distilled water to measure $\mathrm{pH}$ and conductivity was obtained using the alternating current (AC) method.

In this study, undergrowth biomass was found by harvesting all aboveground herbaceous growth, drying to constant weight and then weighing the dried material $\left(\mathrm{g} / \mathrm{m}^{2}\right)$. Shrub biomass was estimated non-destructively by building a testability-factor estimation model based on quantification theory (Zhao, 2004). The percent cover of herbaceous undergrowth was assessed visually in the $2 \mathrm{~m} \times 2 \mathrm{~m}$ sub-plots. The percent cover of shrubs was calculated using crown amplitudes and the sub-plot area. The number of individual plants was divided by the total area to get shrub density for each 
main plot in each type of sand dune. The average crown radius was calculated by averaging four measurements of shrub radii taken in different directions $(\mathrm{N}, \mathrm{E}, \mathrm{S}, \mathrm{W})$ (Gill et al., 2000).

Within a given environment, individuals of the same tree species and of the same age should respond to the environment in a consistent way (Frost and Rydin, 2000). Hence, basal diameter (the diameter of the main stem, i.e. ramet, or of the thickest and strongest stem if there was more than one) and height (the vertical height at the center of the plant) were used as indicators of individual size/age, in determining the composition of the population. In order to describe population structure in greater detail, the classification system used here for grouping plants differs from that of previous studies (Song et al., 2011). Plants were divided into several basal diameter and height classes. The number of individuals falling into each class was tallied for each transect to form a basic data set for population structure analysis. Histograms were used to help illustrate and aid in the interpretation of the diameter and height distributions.

Population dispersion indices are important indicators of the spatial distribution patterns of populations and may be calculated based on field survey data. Various indices have been proposed to describe the degree of spatial clustering in study populations, with different merits. In this study, using plot survey data, the DPS software package was used to calculate several aggregation indices for Haloxylon populations across transects and sampling locations.

\section{Results and analysis}

\section{Primary population characteristics}

Characteristics of Haloxylon populations found in all four dune habitats and three transects are summarized in Table 2, and reveal that average basal diameter, biomass, height and percent cover differed among transects and according to position on the dune. The biomass and percent cover of both Haloxylon and the grasses, as well as Haloxylon stand density, were significantly higher in F plots than in $\mathrm{M}$ or S plots. Plant biomass on the east side of the dunes was lowest in F, between dunes it was lowest in $\mathrm{M}$, and on the dune tops lowest in S. Table 2 reveals a significant decrease in Haloxylon population density from the south (4445 trees/ha) to the central desert (481 trees/ha), although the accompanying shrub species Calligonum leucocladum covered more area in the $S$ versus M plots. Tree density between dunes (6133 trees/ha) was higher than in any of the other three sample locations on the dunes in F, but not in the other two zones. Trends in biomass and percent cover for Haloxylon and the grasses were consistent.In contrast to density, the tree morphological parameters (crown radius, diameter and height) showed a different trend across zones, increasing from $F$ to $S$ and then decreasing in $\mathrm{M}$ (Table 2). Among dune habitats, within the $\mathrm{F}$ area, dune tops had the largest average basal diameter at $4.11 \mathrm{~cm}$, whereas dune valleys had the lowest average basal diameter at $1.68 \mathrm{~cm}$, owing to a high proportion of young seedlings. The mean basal diameter and height of Haloxylon individuals was greatest on dune tops in S. For the $\mathrm{M}$ zone, trees on the east-facing slope had the largest mean basal diameter and height. Apart from the size of the trees, the number of stems differed slightly among transects (Table 2), and the leaf area index decreased substantially from the south to central desert.

Looking at Haloxylon recruitment patterns, there were significant differences among populations from the different zones. There were few recruits in $\mathrm{M}$ or $\mathrm{S}$, while the 
density of recruits was significantly higher in F, especially between dunes. Recruit density increased from central (52 individuals/ ha) to south Gurbantunggut desert (667 individuals/ ha). The relatively high recruit density in $\mathrm{F}$ may indicate a relatively younger population in $\mathrm{F}$ compared to $\mathrm{M}$, perhaps due to more favorable habitat. Indeed, in $\mathrm{F}$, recruits mainly occurred around established plants, where high soil moisture conditions may favor renewal; however, recruit survival and growth rates are extraordinarily low owing to high intraspecific competition (Wei, 2006). In the calculation of percent cover, physical and biological crusts were excluded. Haloxylon individuals of diameter between $0-0.5 \mathrm{~cm}$ were considered to be recruits.

Table 2. Basic characteristics of Haloxylon populations in different habitats

\begin{tabular}{|c|c|c|c|c|c|c|c|c|c|c|}
\hline Terrain & \multicolumn{5}{|c|}{ F. } & \multicolumn{5}{|c|}{ S. } \\
\hline $\begin{array}{l}\text { Characteristic } \\
\text { parameters }\end{array}$ & valley & $\begin{array}{l}\text { Lee } \\
\text { ward } \\
\text { slope }\end{array}$ & top & $\begin{array}{l}\text { Wind } \\
\text { ward } \\
\text { slope }\end{array}$ & mean & valley & $\begin{array}{l}\text { Lee } \\
\text { ward } \\
\text { slope }\end{array}$ & top & $\begin{array}{l}\text { Wind } \\
\text { ward } \\
\text { slope }\end{array}$ & mean \\
\hline $\begin{array}{c}\text { biomass of } \\
\text { Haloxylon }\left(\mathrm{g} \cdot \mathrm{m}^{-2}\right)\end{array}$ & 710 & 652 & 673 & 685 & 680 & 120 & 140 & 350 & 260 & 217 \\
\hline $\begin{array}{c}\text { biomass of grass } \\
\left(\mathrm{g} . \mathrm{m}^{-2}\right)\end{array}$ & 54.4 & 38.6 & 44.5 & 43.96 & 45.3 & 37.6 & 53.9 & 41.5 & 53.46 & 46.6 \\
\hline Stand density & 6133 & 3175 & 3280 & 3733 & 4445 & 325 & 561 & 635 & 545 & 516 \\
\hline $\begin{array}{c}\text { Calligonum } \\
\text { leucocladum } \\
\text { density (strain } \\
/ \mathrm{hm}^{2} \text { ) }\end{array}$ & 0 & 0 & 0 & 0 & 0 & 140 & 135 & 250 & 255 & 195 \\
\hline Coverage (\%) & 51.7 & 43.5 & 51.0 & 47.9 & 49 & 24.6 & 32.9 & 28.4 & 36.9 & 30.1 \\
\hline $\begin{array}{l}\text { diameter (mean) } \\
(\mathrm{cm})\end{array}$ & 1.68 & 3.09 & 4.11 & 3.43 & 3.08 & 2.25 & 2.08 & 3.49 & 2.28 & 2.53 \\
\hline $\begin{array}{l}\text { Height(mean) } \\
(\mathrm{cm})\end{array}$ & 48.7 & 147.2 & $\begin{array}{c}136 . \\
8\end{array}$ & 144.5 & 119.3 & 110 & 81.7 & 123 & 81.47 & 99.0 \\
\hline crown radius $(\mathrm{cm})$ & 32.4 & 61.9 & 58.3 & 63.4 & 47.6 & 56.5 & 47.3 & 70.8 & 63.9 & 64.7 \\
\hline $\begin{array}{c}\text { recruits } \\
\text { density(strain } \\
\left./ \mathrm{hm}^{2}\right)\end{array}$ & 1300 & 20 & 0 & 140 & 365 & 0 & 180 & 140 & 0 & 80 \\
\hline $\begin{array}{l}\text { The number of } \\
\text { stems } \\
\text { (ramification } \\
\text { below } 0.5 \mathrm{~m} \text { ) }\end{array}$ & \multicolumn{5}{|c|}{$1-8$} & \multicolumn{5}{|c|}{$1-18$} \\
\hline terrain & \multicolumn{8}{|c|}{ M. } & \multicolumn{2}{|c|}{ total } \\
\hline $\begin{array}{l}\text { Characteristic } \\
\text { parameters }\end{array}$ & \multicolumn{2}{|c|}{ b valley } & $\begin{array}{l}\text { Lee ward } \\
\text { slope }\end{array}$ & \multicolumn{2}{|c|}{ top } & \multicolumn{2}{|c|}{$\begin{array}{l}\text { Wind ward } \\
\text { slope }\end{array}$} & mean & \multicolumn{2}{|c|}{ dune } \\
\hline $\begin{array}{c}\text { biomass of } \\
\text { Haloxylon }\left(\mathrm{g} . \mathrm{m}^{-2}\right)\end{array}$ & \multicolumn{2}{|l|}{58} & 220 & \multicolumn{2}{|c|}{176.3} & \multicolumn{2}{|l|}{178} & 158 & \multicolumn{2}{|c|}{1391} \\
\hline $\begin{array}{l}\text { biomass of grass } \\
\left(\mathrm{g} . \mathrm{m}^{-2}\right)\end{array}$ & \multicolumn{2}{|c|}{45.73} & 30.7 & \multicolumn{2}{|c|}{10.7} & \multicolumn{2}{|l|}{24.25} & 27.6 & \multicolumn{2}{|c|}{40.8} \\
\hline Stand density & \multicolumn{2}{|l|}{393} & 201 & \multicolumn{2}{|c|}{608} & \multicolumn{2}{|l|}{305} & 481 & \multicolumn{2}{|c|}{1701} \\
\hline $\begin{array}{l}\text { Calligonum } \\
\text { leucocladum } \\
\text { density (strain } \\
\left./ \mathrm{hm}^{2}\right)\end{array}$ & \multicolumn{2}{|c|}{350} & 310 & \multicolumn{2}{|c|}{70} & \multicolumn{2}{|l|}{420} & 287 & & \\
\hline Coverage (\%) & \multicolumn{2}{|l|}{14.8} & 13.9 & \multicolumn{2}{|c|}{7.81} & \multicolumn{2}{|l|}{9.27} & 11.0 & \multicolumn{2}{|c|}{30.5} \\
\hline $\begin{array}{l}\text { diameter (mean) } \\
(\mathrm{cm})\end{array}$ & \multicolumn{2}{|c|}{2.75} & 3.54 & \multicolumn{2}{|c|}{2.09} & \multicolumn{2}{|l|}{2.17} & 2.64 & 2. & 75 \\
\hline $\begin{array}{l}\text { Height(mean) } \\
(\mathrm{cm})\end{array}$ & 106. & & 157.5 & & 5.47 & 90.5 & & 112.8 & 11 & 0.4 \\
\hline
\end{tabular}




\begin{tabular}{|l|c|c|c|c|c|c|}
\hline crown radius $(\mathrm{cm})$ & 37.2 & 60.4 & 49.8 & 46.0 & 48.9 & \\
\hline $\begin{array}{c}\text { recruits } \\
\text { density(strain } \\
\left./ \mathrm{hm}^{2}\right)\end{array}$ & 0 & 60 & 60 & 140 & 65 & 170 \\
\hline $\begin{array}{c}\text { The number of } \\
\text { stems } \\
\text { (ramification } \\
\text { below 0.5 m) }\end{array}$ & \multicolumn{7}{|c|}{$1-22$} & & \\
\hline $\begin{array}{l}\text { In the calculation of percent cover, physical and biological crusts were excluded. } \\
\text { Haloxylon individuals of diameter between 0- } 0.5 \mathrm{~cm} \text { were considered to be recruits. }\end{array}$ \\
\hline
\end{tabular}

\section{The basal diameter structure of Haloxylon populations in different habitats}

Although grouping individuals based on stem diameter versus age may produce different distributions, the two methods are consistent in predicting species' responses to the environment (Frost and Rydin, 2000). Trees are often classified according to basal diameter or height, in order to analyze the population's structure (Liu et al., 2012; Song et al., 2008). Thus, in this study, diameter classes were used to gain insight into Haloxylon population characteristics. The basal diameter data for Haloxylon populations from different areas of the dunes, across the three transect zones, are presented in Figure 5. The basal diameter distributions were positively skewed (asymmetric) in all zones, with a "reverse J" shape. This indicates a predominance of small individuals (diameter of $0-3 \mathrm{~cm}$ ), a pattern that was particularly marked in F (Fig. 5 ). The occurrence of young trees across transects reveals that Haloxylon populations are relatively stable with good regeneration potential. No individuals in the largest diameter class (more than $20 \mathrm{~cm}$ ) were found on the east side of the dunes in $\mathrm{F}$ or in dune valleys in $S$ and $M$. The average diameter of all trees surveyed in $F(+4,000$ trees) was $3.08 \mathrm{~cm}$, and more than $70 \%$ of trees had a basal diameter of $3 \mathrm{~cm}$ or less, with trees of diameter $0-1 \mathrm{~cm}$ accounting for the highest percentage of the total at $43 \%$. There were only four plants with a basal diameter greater than $25 \mathrm{~cm}$ in the whole $2.4 \mathrm{hm}^{2}$ study area; these were located on dune tops in $\mathrm{F}$ and $\mathrm{S}$ zones, and on windward slopes in $\mathrm{S}$ and $\mathrm{M}$ zones. The largest basal diameter, $37 \mathrm{~cm}$, was recorded on the top of an $\mathrm{F}$ dune, however diameters between dunes in $\mathrm{F}$ were significantly lower than in other transects and sample locations. In the F transect, trees of small basal diameter $(0-1 \mathrm{~cm})$ accounted for the greatest proportion (64\%) of individuals on the plain between dunes, whereas in the other three dune habitats $1-2 \mathrm{~cm}$ Haloxylon trees were the most common. The first peak of the fixed dune diameter distribution (dune valley populations) was the highest, but there was also a second peak in the next diameter class (other sample locations), which was different from the other zones. The distributions for dune top and leeward slope populations in $\mathrm{S}$ were relatively flat, with abundance gradually decreasing as basal diameter increased, but dune bottom and west slope populations peaked at $1-2 \mathrm{~cm}$. Dune top populations had a significantly higher proportion of trees of $10-20 \mathrm{~cm}$ than other populations. Haloxylon trees of $6-7 \mathrm{~cm}$ accounted for a significant proportion of the total in $\mathrm{M}$ plots, although the overall trend again showed that young recruits were predominant. 

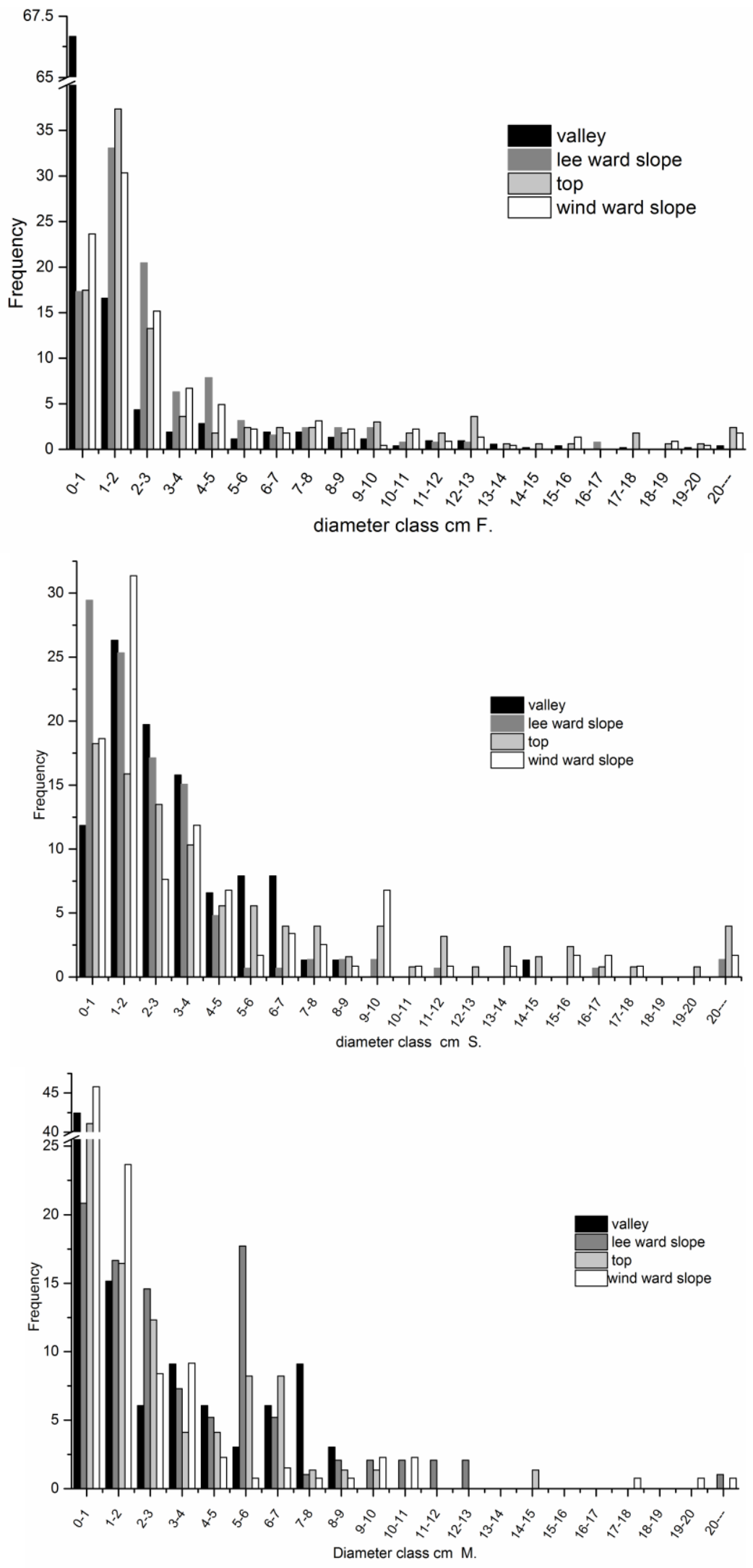


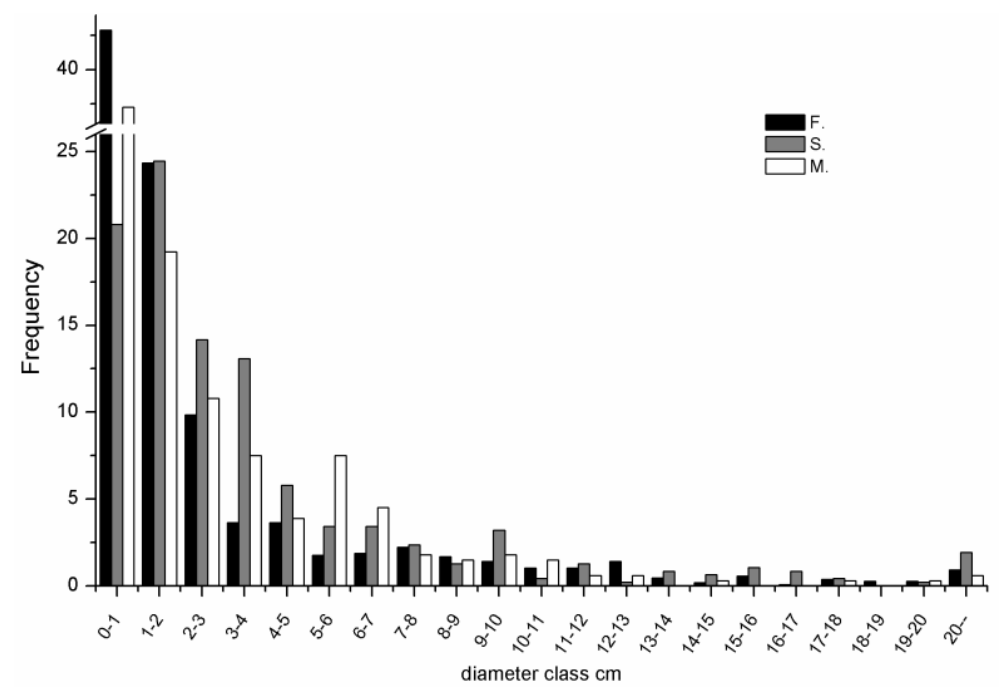

Figure 5. Basal diameter structure of Haloxylon populations in different habitats (1class $\leq 1 \mathrm{~cm} ; 1 \leq 2$ class $\leq 2 \mathrm{~cm} ; 2 \leq 3$ class $\leq 3 \mathrm{~cm} ; 3 \leq 4 \leq 4 \mathrm{~cm} ; 4 \leq 5$ class $\leq 5 \mathrm{~cm} ; 5 \leq 6$ class $\leq 6 \mathrm{~cm} ; 6 \leq 7$ class $\leq 7 \mathrm{~cm} ; 7 \leq 8$ class $\leq 8 \mathrm{~cm} ; 8 \leq 9$ class $\leq 9 \mathrm{~cm} ; 9 \leq 10$ class $\leq 10 \mathrm{~cm} ; 10 \leq 11$ class $\leq 11 \mathrm{~cm} ; 11 \leq 12$ class $\leq 12 \mathrm{~cm} ; 12 \leq 13$ class $\leq 13 \mathrm{~cm} ; 13 \leq 14$ class $\leq 14 \mathrm{~cm} ; 14 \leq 15$ class $\leq 15 \mathrm{~cm} ; 15 \leq 1$ class $6 \leq 16 \mathrm{~cm} ; 16 \leq 17$ class $\leq 17 \mathrm{~cm} ; 17 \leq 18$ class $\leq 18 \mathrm{~cm} ; 18 \leq 19$ class $\leq 19 \mathrm{~cm} ; 19 \leq 20$ class $\leq 20 \mathrm{~cm} ; 21$ class $\geq 20 \mathrm{~cm}$.)

\section{The height structure of Haloxylon populations in different habitats}

The distribution of plant heights varied among Haloxylon populations from different transects and locations on the dunes (Fig. 6). As with basal diameters, height distributions were also positively skewed ("reverse J" shape) across all zones, with the distributions generally peaking at $0-50 \mathrm{~cm}$, except for on dune tops and windward slopes in $\mathrm{F}$ and in dune valleys in $\mathrm{S}$, where the first peak occurred at $50-100 \mathrm{~cm}$. Some distributions had second peaks at $150-250 \mathrm{~cm}$. First peaks were generally more pronounced than second peaks, except for in the $\mathrm{S}$ zone. In the $\mathrm{F}$ transect, there was a single, large peak in the first height class, a different pattern than for the other dune habitats. In the $\mathrm{S}$ zone, there were two distinctive peaks. In the $\mathrm{M}$ zone, the distribution of plant heights varied across dune sample locations, but all peaked at a height of $50 \mathrm{~cm}$. There was a second peak at the height of $100 \mathrm{~cm}$ (frequency decreased from dune valleys, to tops, to leeward slopes, to windward slopes) showing that all Haloxylon populations required similar environmental conditions for growth and development. In addition, field surveys found that individuals with a height of $0-20 \mathrm{~cm}$ were seedlings, and the proportion of seedlings was highest in populations growing at the bottom of fixed dunes (versus other population types). The population structure of Haloxylon in fixed dunes indicated a growing population. However, excluding the plants in the 0$50 \mathrm{~cm}$ class in F, populations of Haloxylon had an almost symmetric height distribution, with the largest trees being more than $600 \mathrm{~cm}$ tall and the smallest individuals less than 5 $\mathrm{cm}$. In $\mathrm{S}$ and $\mathrm{M}$, Haloxylon height distributions were irregular or tended towards an uneven shape. 

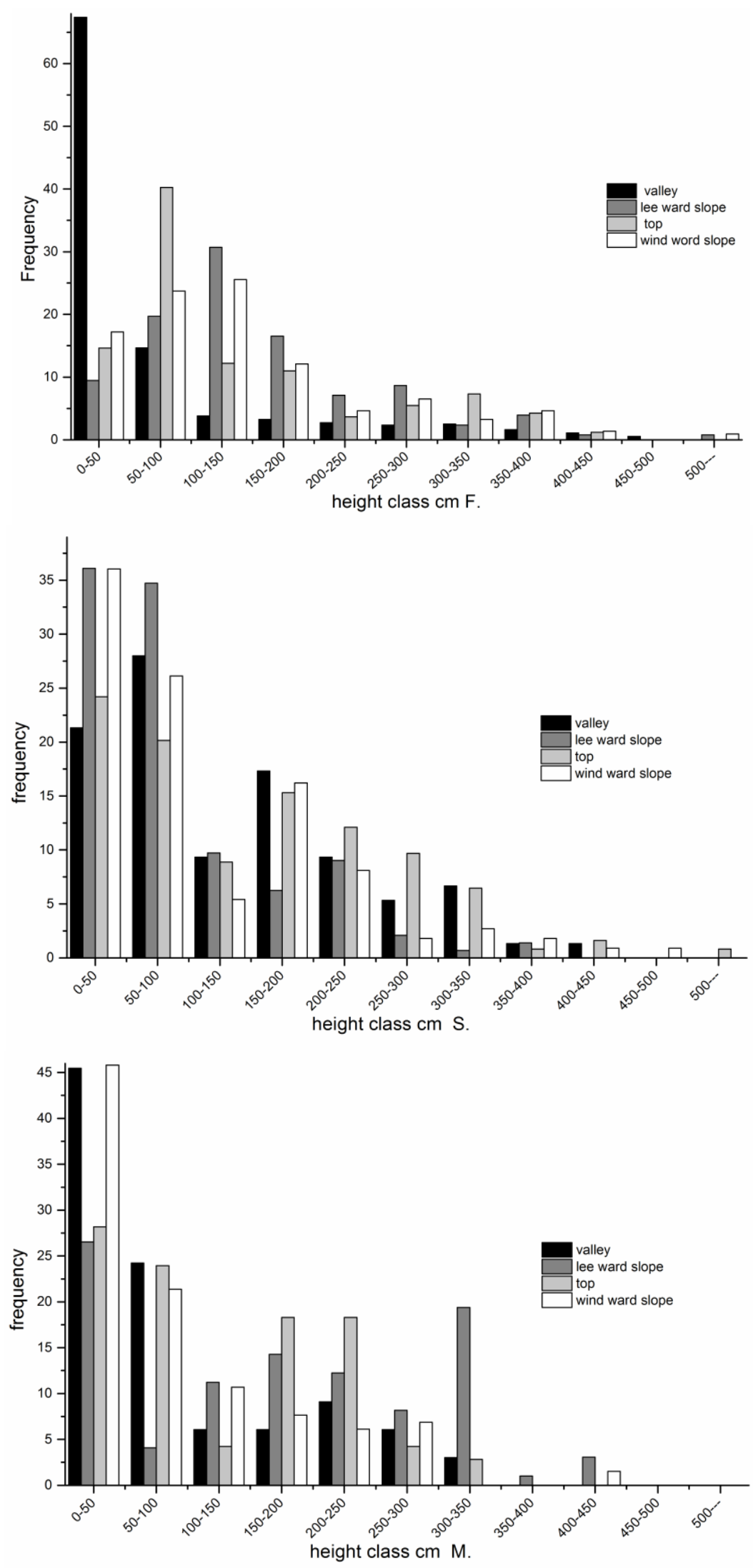


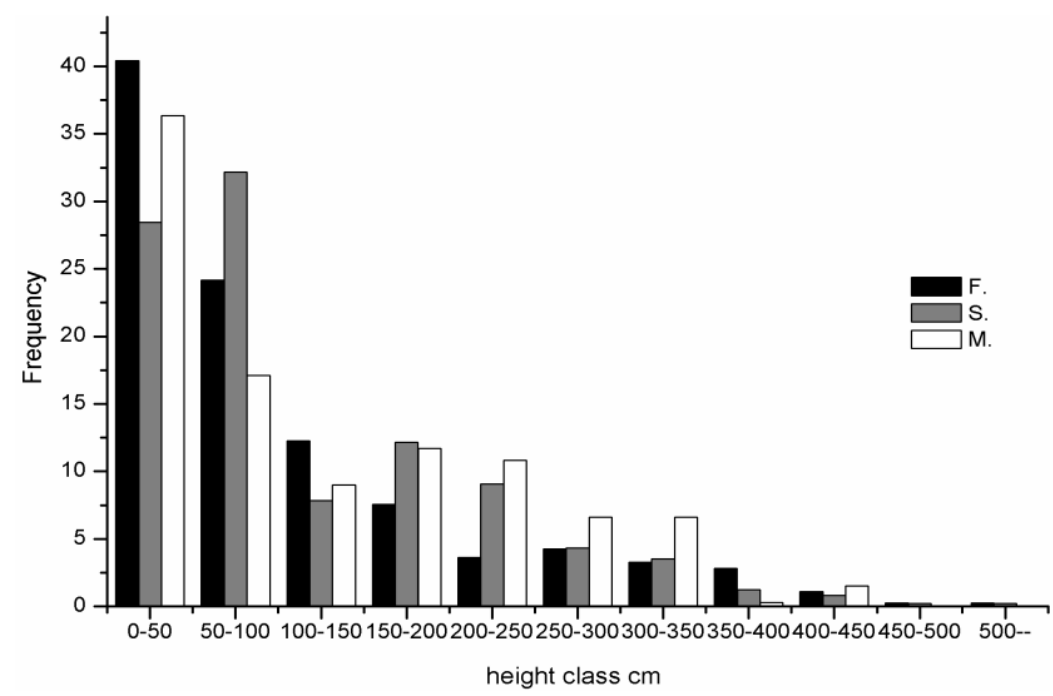

Figure 6. Plant height structure of Haloxylon populations in different habitats (1class $\leq 50 \mathrm{~cm} ; 50 \leq 2$ class $\leq 100 \mathrm{~cm} ; 100 \leq 3$ class $\leq 150 \mathrm{~cm} ; 150 \leq 4$ class $\leq 200 \mathrm{~cm} ; 200 \leq 5 \mathrm{class} \leq 250 \mathrm{~cm} ; 2$ $50 \leq 6$ class $\leq 300 \mathrm{~cm} ; 300 \leq 7$ class $\leq 350 \mathrm{~cm} ; 350 \leq 8$ class $\leq 400 \mathrm{~cm} ; 400 \leq 9$ class $\leq 450 \mathrm{~cm} ; 450 \leq 10$ class $\leq 50$ $0 \mathrm{~cm} ; 11$ class $\geq 500 \mathrm{~cm}$.)

\section{Spatial distribution analysis for Haloxylon populations in different habitats}

The spatial distributions of Haloxylon populations in different zones and positions on the dunes were analyzed using aggregation indices, including indicators such as the I index, the patchiness index $M * / M$, the Cassie index $C A=\left(S^{2}-X\right) / X^{2}$, the diffusion coefficient $\mathrm{C}$ and the $\mathrm{K}$ index (Table 3). When $\mathrm{I}<1$, individuals are uniformly distributed in space; when $\mathrm{I}=1$, they are randomly distributed; and when $\mathrm{I}>1$, they are clumped (an aggregated distribution). When the patchiness index $M^{*} / \mathrm{M}=1$, the population has a random distribution; when $M^{*} / \mathrm{M}>1$, it is clumped; and when $\mathrm{M}^{*} / \mathrm{M}$ $<1$, it is uniform. When $\mathrm{CA}<0$, it is a uniform distribution; when $\mathrm{CA}=0$, it is random; and when $C A>0$, it is clumped. The diffusion coefficient $C=S^{2} / X$ is used to test whether a population is randomly distributed in space or not; when $\mathrm{C}=1$, it is random; when $\mathrm{C}<1$, it is clumped and when $\mathrm{C}>1$, individuals are spatially aggregated. When the negative binomial distribution index, $\mathrm{K}=\mathrm{X}^{2} /\left(\mathrm{S}^{2}-\mathrm{X}\right)$, is $\mathrm{K}<0$, it is a uniform distribution; when $\mathrm{K}>0$, it is clumped; and when $\mathrm{K}$ tends to $+\infty$, it is random.

The index calculations showed that all 60 Haloxylon sample populations (in the $10 \mathrm{~m} \times 10 \mathrm{~m}-20 \mathrm{~m} \times 20 \mathrm{~m}$ quadrats) had clustered distributions. The diffusion coefficient $\mathrm{C}$ is known to be a reliable indicator of the spatial distribution of individuals within a population; it is used to test if there is any deviation from a stochastic distribution(Yan et al., 2012). The larger the $\mathrm{C}$ value is, the higher the degree of clustering within the population, and vice versa. As shown in Table 3, the $\mathrm{C}$ values of Haloxylon populations in semi-fixed and movable dunes were generally large, and the highest $\mathrm{C}$ value, of 741.73, was found for populations at the top of the semi-fixed dune, whereas the minimum value of 4.99 was found at the top of fixed dunes. Fixed dune populations had a lower degree of clustering. The mean $\mathrm{M}^{*}$ in Table 3 is the average number of neighbors for each Haloxylon individual in a one hectare area. $\mathrm{M}^{*}$ was greatest at the bottom of the fixed dune, and on the west slope of the moveable dune, consistent with patterns in plant density (see Table 2). However, the highest percent cover values for the movable dune occurred not on the west but on the east slope, perhaps due to the 
smaller basal diameters of Haloxylon on the west slope. These results also indicate that percent cover may not be equatable with density, because of the impact of the tree crown.

Table 3. Spatial distribution of Haloxylon populations in different habitats

\begin{tabular}{|c|c|c|c|c|c|c|c|}
\hline Terrain & Indicators & $\mathbf{I}$ & $\mathbf{M} * / \mathbf{M}$ & $\mathbf{C a}$ & $\mathbf{C}$ & $\mathbf{K}$ & The result \\
\hline Fixed & Valley & 57.04 & 1.009 & 0.0093 & 58.04 & 107.5 & Claster \\
sand & East side & 14.48 & 1.004 & 0.0046 & 15.48 & 219.18 & Claster \\
dunes & Top & 3.00 & 1.001 & 0.0012 & 4.99 & 821.56 & Claster \\
& West side & 85.96 & 1.02 & 0.023 & 86.96 & 43.42 & Claster \\
Semi & Bottom & 740.73 & 3.279 & 2.2792 & 741.73 & 0.43 & Claster \\
fixed snd & East side & 153.67 & 1.329 & 0.3293 & 154.67 & 3.03 & Claster \\
dunes & Top & 43.13 & 1.081 & 0.0815 & 44.13 & 12.26 & Claster \\
& West side & 155.19 & 1.284 & 0.2828 & 156.19 & 3.51 & Claster \\
Mobile & Bottom & 286.1 & 1.726 & 0.727 & 287.1 & 1.37 & Claster \\
sand & East side & 133.8 & 1.185 & 0.186 & 134.8 & 5.38 & Claster \\
dunes & Top & 152.2 & 1.25 & 0.25 & 153.2 & 3.99 & Claster \\
& West side & 334.4 & 1.415 & 0.415 & 335.4 & 2.4 & Claster \\
\hline
\end{tabular}

\section{Conclusions and discussion}

Soil organic matter, texture and edaphic horizons are the most important properties of a site with regard to water availability of the soils and the differential response of plants (Troeh and Thompson, 2005). In this study, we only considered the surface edaphic horizon, as this is the one that interacts most actively with plants in the desert. Here, soil moisture and organic matter content decreased with altitude and differed significantly among three phytogeographic zones from south to central Gurbantunggut desert. Differences in soil organic matter, moisture and texture among the study geomorphological positions on dunes within the same zone (i.e. dune bottom, top or east/west slopes), produced differences in Haloxylon population characteristics. Hence, the distribution patterns and characteristics of Haloxylon populations may serve as relevant barometers of an ecosystem's sensitivity or resilience to external (environmental and anthropogenic) disturbances, although Haloxylon spp. have exceptionally broad ecological tolerances, being the main woody species in central Asian desert ecosystems ( $\mathrm{Li}, 2013 \mathrm{a})$. Haloxylon plays an important role in maintaining the stability of the entire desert ecosystem (Huang et al., 2009) and is considered a dominant and keystone species. In the 1970's, anthropogenic disturbance resulted in reductions in Haloxylon populations ( $\mathrm{Si}, 2011$ ), which also fed back to influence the environment, especially in certain edaphic characteristics. The mutual feedbacks between vegetation and the environment are of relevance to ecohydrological processes and to sand-binding vegetation systems in sandy desert regions of China ( $\mathrm{Li}, 2013 \mathrm{~b}$ ). Several factors, including the bulk of seed rain occurring near established individuals (Shi et al., 2010) and the increase in soil nutrients and soil moisture (via hydraulic lift in plant roots) around mature plants (Li, 2007; Lamusa et al., 2008; Yuan et al., 2012) promote regeneration (i.e. most seedlings occur around mature plants, hence the higher the density of Haloxylon, the higher the recruit density).

Quantification in study plots indicated a significant decrease in Haloxylon density from the south to the central desert and a high correspondence between plant height and diameter, which both followed asymmetric distributions ("reverse J" shaped) in all 
populations. The diameter and height distributions across the three desert zones (Fig.7) clearly indicated growing populations, as young plants accounted for the highest proportion of individuals, with progressively fewer individuals in each larger size class. Tree density in the valleys between dunes was higher than in any other location on the dune in F, but this pattern was not found in the other zones. Few recruits were found in the central desert, but their density increased from the central to the south Gurbantunggut desert. In the drier $\mathrm{M}$ and $\mathrm{S}$ zones, trees were distinctly more scattered suggesting lower overall tree biomass, an impression confirmed in Figure 7, where there was less variation in tree size (fewer size classes) in $\mathrm{M}$ and $\mathrm{S}$ compared to $\mathrm{F}$. These population patterns and trait distributions are consistent with previous studies (Song et al., 2011; Qian et al., 2007) that found that biomass is lower in the central desert. The availability of soil moisture and total precipitation limit plant density (Zhu and Jia, 2011). Previous studies have indicated that self-thinning processes occurred in Haloxylon plantations after 10 years of growth (Chang et al., 2008) and that plant survival decreased over time. Here, the abundance of Haloxylon trees also decreased with size (Fig. 7). In the plantation study, trees had access to ground water for the first 20 years, and yet there were still high mortality rates. The ground water table may perhaps have been too low to support normal physiological activity, or this mortality may have been observed for other reasons(Zeng et al., 2012; Zhang, 2010).

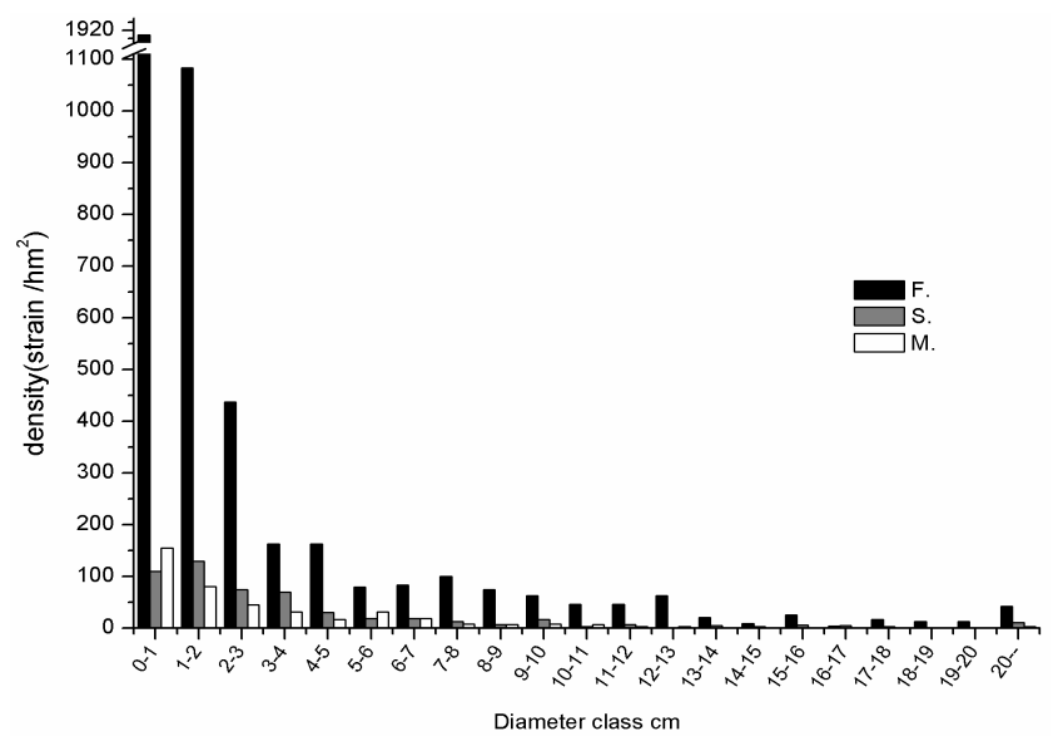

Figure 7. The distribution of plant diameters across the three zones

The biomass of Haloxylon individuals decreased towards the central desert These results suggest that Haloxylon is adapted to the inner desert drought conditions. Dropping assimilating branches as needed can act to maintain a balance between water supply deficits and water consumption of the assimilating organs; this morphological adjustment can reduce seedling mortality effectively. Greater allocation of photosynthate towards roots can also ensure seedling survival and a quick recovery of growth when adequate water is restored (Tian et al., 2014). In the M zone, plant stems are quickly buried by sand leading to a thin plant shape and proliferation in the number of stems (ramification below 0.5m) compared to other zones (Gai et al., 2008). New recruits were mainly found growing around mature individuals, likely because this is 
where the bulk of the seed rain occurs (Shi et al., 2010), where soil nutrients are most abundant, and where soil moisture is highest owing to hydraulic lift in plant roots (Li, 2007; Lamusa et al., 2008; Yuan et al., 2012). Hence, populations were distributed along an environmental gradient characterized by variation in water availability and soil fertility. The spatial structure of Haloxylon populations indicated clustered distributions in all zones, with recruits strongly clustered in the fixed sand dunes. Haloxylon species have a good ability to tolerate broad climatic and habitat fluctuations.

Our results illustrate that, apart from the soil physicochemical properties, climatic gradients may also have significant impacts on Haloxylon morphological traits and population structure, but that responses to climatic gradients vary significantly between phytogeographical zones. The population structure and basic characteristics of Haloxylon populations studied here resemble those found in other investigations, where a weak natural regeneration of the species in the central dessert was also observed ( $\mathrm{Si}$, 2011; Huang et al., 2009). Based on demographic behavior, we concluded that populations are growing in abundance in all three zones; however, the density of individuals in the $\mathrm{M}$ zone is too low for long-term persistence, and hence it is still a species of concern; Tree morphological traits (height, diameter, number of stems) vary according to the phytogeographical zones and change over time; and the spatial patterns of Haloxylon individuals in natural stands suggest varying degrees of aggregation.

Acknowledgements. The authors' thanks go to Xingjiang Institute of Ecology and Geography for Education and Research through the Major scientific research projects (973 plan) (No. 2013CB429905), the Xinjiang Natural Science Foundation of Xinjiang (No. 2014211B014) and the National Natural Science Foundation of China (No. 41301205) for funding this research. We thank also the editor and two anonymous reviewers for their constructive comments that greatly improved this paper. We would also like to thank Emily Drummond at the University of British Columbia for her assistance with English language and grammatical editing of the manuscript.

\section{REFERENCES}

[1] Aitken, S.N., Yeaman, S., Holliday, J.A., Wang, T., Curtis-McLaneS. (2008): Adaptation, migration or extirpation: climate change outcomes for tree populations. Evolutionary Applications 1: 1752-4563.

[2] Allan, B., Walter, W., Stefan, Z., et al. (2012): Allometric variability of Haloxylon species in Central Asia. - Forest Ecology and Management 274(15): 1-9.

[3] Bognounou, F., Thiombiano, A., Savadogo, P., Boussim, I.J., Oden, P.C., Guinko, S. (2009): Woody vegetation structure and composition at four sites along a latitudinal gradient in Western Burkina Faso. - Boiset Forets des Tropiques 300: 29-44.

[4] Chang, Z. F., Han, F. G., Zhong, S. N., Zhang, Y. C., He, F. L., Chai, C. W. (2008): Self thinning process of Haloxylon ammodendron planted forest in desert area of Minqin. Acta Botanica Boreali-Occidentalia Sinica 28 (1): 147-154.

[5] Dale, M. (1999): Spatial pattern analysis in plant ecology, - Cambridge. United Kingdom: 151-198.

[6] Fandohan, B., Assogbadjo, A. E., Glele Kakai, R., Sinsin, B. (2011): Geographical distribution, tree density and fruit production of Tamarindus indica L. (Fabaceae) across three ecological regions in Benin. - Fruits 66: 53-62.

[7] Frost, I., Rydin, H. (2000): Spatial pattern and size distribution of the animal dispersed Quercusrobur in two spruce-dominanted forest. - Ecoscience 7: 38-44. 
[8] Gai, S. G., Wang, X. Q., Wan, J. P., Wu, T., Guo, H. X., Quan, Y. W., Jin, X. Q. (2008): Study on Airflow Velocity Change over Semi-fixed Longitudinal Dune Surface in Gurbantunggut Desert. - Journal of Soil and Water Conservation 22(4): 30-34.

[9] Gill, S. J., Biging, G. S., Murphy, E. C. (2000): Modeling conifer tree crown radius and estimating canopy cover. - Forest Ecology and Management 126(3): 405-416.

[10] $\mathrm{Hu}, \mathrm{W}$. K. (1985): In southern junggar basin h. ammodendron productivity evaluation and reasonable development way of the desert. - Arid Zone Research 2: 40-45.

[11] Huang, P. Y., Xiang, B., Li, Q. J., Xu, Z. H. (2009): Relationship between Haloxylon ammodendron seedling dynamics and habitat before summer. - Journal of Desert Research 29(1): 87-94.

[12] Ivanov, L. A., Ronzhina, D. A., Ivanova, L. A. (2008): Changes in Leaf Characteristics as Indicator of the Alteration of Functional Types of Steppe Plants along the Aridity Gradient. - Russian Journal of Plant Physiology 55(3): 301-307.

[13] Jeltsch, F, Moloney, K, Milton, S. J. (1999): Detecting process from snapshot pattern: lessons from tree spacing in the southern Kalahari. - Oikos 14: 451-466.

[14] Kikkawa, J., Anderson, D. J. (1984): Community Ecology: Pattern and Process. Melbourne. - Blackwell Scientific Publication.

[15] Lamusa, A., Jiang, D. M., Luo, Y. M. (2008): Review on Study Progress of Hydraulic Lift in plant Roots. - Arid Zone Research 25(2): 236-241.

[16] Li, J., Zhao, C. Y., Zhu, H., Wang, F. (2007): Species effect of Tamaix spp. and Haloxylon ammodendron on shrub's "fertile island". - Acta Ecologica Sinica 27(12): 5138-5147.

[17] Li, X., Jiang, J., Song, C. W., et al. (2013a): Growth and Adaptation of Haloxylon ammodendron Seedlings in Different Habitats in Guerbantunggut Desert. - Journal of desert research 33(1): 101-105.

[18] Li, X. R., Zhang, Z. S., Huang, L., et al. (2013b): Review of the ecohydrological processes and feedback mechanisms controlling sand-binding vegetation systems in sandy desert regions of China. - Chinese Sci Bull 58(5): 397-410.

[19] Liang, Y. Q., Zhao, L. Z. (1982): The protection and development of the Desert Haloxylon forest. - Natural resources 5: 23-24.

[20] Liu, R. T., Zao, X. Y. (2009): Soil macrofauna response to sand dune conversion from mobile dunes to fixed dunes in Horqin sandy land, northern China. - European Journal of Soil Biology 45: 417-422.

[21] Liu, S. J., Yuan, H. B., Zhang, J. C., Tang, J. N. (2012): Factor Analysis of Natural Environmental Elements and Characteristics of Typical Populations in Kumtagh Desert. Acta Bot. Boreal. Occident. Sin. 32(9): 1874-1881.

[22] Lykke, A. M., Fog, B., Madsen, J.E. (1999): Woody vegetation changes in the Sahel of Burkina Faso assessed by means of local knowledge, aerial photos and botanical investigations. - Geografisk Tidsskift, Danish Journal of Geography 2: 57-68.

[23] Mueller, R. C., Scudder, C. M., Porter, M. E., Trotter, R. T. I. I. I., Gehring, C. A., Whitham, T. G. (2005): Differential tree mortality in response to severe drought: evidence for longterm vegetation shifts. - Journal of Ecology 93: 1085-1093.

[24] Nacoulma, B. M. I., Schumann, K., Traore, S., Bernhardt-Romermann, M., Hahn, K.,Wittig, R., Thiombiano, A. (2011): Impacts of land-use on West African savanna vegetation: a comparison between protected and communal area in Burkina Faso. Biodiversity and Conservation 20: 3341-3362.

[25] Nyongesah, M. J., Wang, Q. (2013): Variation of photosynthesis and pigment concentration relative to irradiance and nitrogen content for two coexisting desert shrubs. - Ecological Engineering 58: 238-248.

[26] Qian, Y. B., Wu, Z. N., Wang, Z. C., et al. (2011): Spatial variation of physical and chemical properties for eolian sand soil at longitudinal dune scale in southern. Gurbantunggut Desert Geographical Research 30(7): 1178-1186. 
[27] Qian, Y. B., Wu, Z. N., Zhang, L. Y., Zhao, R. F., Wang, X. Y., Li, Y. M. (2007): Spatial patterns of ephemeral plants in Gurbantunggut Desert. - Chinese Science Bulletin 52( 22): 3118-3127.

[28] Qian, Y. B., Zhang, L. Y., Wu, Z. N. (2003): Characteristics of eco-environment in the margin regions of the junggar basin. - Xinjiang. A rid Land Geography 26(1): 30-36.

[29] Saei, E. K., Abedini, S., Ghaderi, N., Soltani, A. (2014): Spatial distribution pattern of oak and almond trees on Chahartagh forest reservation site. - International Journal of Biosciences 4(3):158-163.

[30] Sambare, O., Bognounou, F., Wittig, R., Thiombiano, A. (2011): Woody species composition, diversity and structure of riparian forests of four watercourses types in Burkina Faso. - Journal of Forestry Research 22: 145-158.

[31] Shi, G. L., Bai, B., Lu, C. H. (2010): Seed rain and seed bank of Chinese yew (Taxus chinensis var. mairei) population in Tianmu Mountain. - Acta Ecologica Sinica 30(5): 276-279.

[32] Si, L. M. (2011): Reasons for the degeneration of Haloxylon ammodendron populations in the western part of Gurbantunggut Desert. - Shihezi University 12-29.

[33] Si, L. M., Liu, T., Yu, X. (2010): Soil factors limiting population regeneration of degenerated Haloxylon ammodendrnn in Gurbantonggut Desert. - Chinese Journal of Ecology, 29: 1925-1930.

[34] Song, Y. Y., Chu, G. M., Hu, X. J. (2011): Relationship of Diameter-class and Age-class of Haloxylon ammodendron Population in Gurbantonggut Desert. - Acta Bot. Boreai. Occident. Sin. 31(4): 0808-0814.

[35] Song, Y. Y., Liu, C. Q., Zhao, Z. Y. (2008): Quantity Dynamics of Haloxylon ammodendron Population in Different Habitats in Shihezi Region, - Bot. Boreal. Occident. Sin. 28 (10): 2118-2124.

[36] Swenson, N. G., Enquist, B. J. (2007): Ecological and evolutionary determinants of a key plant functional trait: wood density and its community-wide variation across latitude and elevation. - American Journal of Botany 94: 451-459.

[37] Tian, Y., Tashpolat, T., Li, Y., Tang, L. S., Fan, L. L. (2014): The survival and above/below ground growth of Haloxylon ammodendron seedling. - Acta Ecologica Sinica 34(8): 2012-2019.

[38] Troeh, F. R., Thompson, L. M. (2005): Soils and Soil Fertility. - Blackwell Publishing, Ames. 201-231.

[39] Wang, X. Q., Lei, J. Q., Jiang, J., Qian, Y. B. (2003): Pattern of blown sand motion on longitudinal dune surface and its threat to linear engineering projects in Gurbantonggut desert, Xinjiang, China. - Arid Land Geography 2: 143-149.

[40] Wang, X. Q., Zhao, C. J. (2002): Sand surface change and natural species entrance in straw Barrier System in Gurbantonggute Desert, Xinjiang, China. - Arid Land Geography 25(3): 201-207.

[41] Wei, J., Zhang, X. M., Shan, L. S., Yan, H. L., Liang, S. M. (2006): Seedling growth dynamic of Haloxylon ammodendron and acclimation strategy in hinterland of desert. Scientia Sinica Terrae S2:95-102.

[42] Wu, M., Zhang, W. H., Ma, C., Zhou, J. Y. (2013): Changes in Morphological, Physiological, and Biochemical Responses to Different Levels of Drought Stress in Chinese Cork Oak (Quercus variabilis Bl.) Seedlings. - Russian Journal of Plant Physiology 60(5): 681-692.

[43] Yan, D. F., Wang, Y. N., Yang, X. T. (2012): Structure and Spatial Distribution Patterns of the Main Woody Plant Populations of Oak Natural Secondary Forests in Baotianman Nature Reserve, Henan Province. - Journal of Northwest Forestry University 27(3): 155159. 
[44] Yuan, G. F., Zhang, P., Xue, S. S., Zhuang W. (2012): Change characteristics in soil water content in root zone and evidence of root hydraulic lift in Tamarix ramosissima thickets on sand dunes. - Chinese Journal of Plant Ecology 36(10): 1033-1042.

[45] Zeng, X. L., Liu, T., Zhang, W. B., Sun, Q. M., Shen, X. Y., Si, L. M. (2012): Variations in groundwater levels and quality and their effects on vegetation in the western Grurbantonggut Desert. - Acta Ecologica Sinica 32(5): 1490-1501.

[46] Zhang, J.C., Ji, Y.F., Wang, F.L., Chen, F., Wang, J.J., Wang, G.S., Cao, W. (2010): Rain-fed recovery of degenerated artificial Haloxylon ammodendron population in Minqin. - Journal of Northwest Forestry University 25(1): 77-81.

[47] Zhao, C. Y., Song, Y. D., Wang, Y. C., Jiang, P. N. (2004): Estimation of aboveground biomass of desert plants. - Chinese Journal of Applied Ecology 15(1): 49-52.

[48] Zhu, G. L., Mosyakin, S. L., Clemants, S. E. (2004): Haloxylon Bunge (Chenopodiaceae), In Flora of China Editorial Committee (eds) Flora of China (English ed.). - Sci. Press, Beijing/Missouri Botanic Garden Press St. Louis.(5): 395-396.

[49] Zhu, Y. J., Jia, Z. Q. (2011): Soil water utilization characteristics of Haloxylon ammodendron plantation with different age during summer. - Acta Ecologica Sinica 31: 341-346. 